\title{
НЕЙРОЭНДОКРИННЫЕ ОСОБЕННОСТИ РЕГУЛЯЦИИ МЕНСТРУАЛЬНОГО ЦИКЛА У ДЕВОЧЕК С ОЖИРЕНИЕМ
}

\author{
Е.М. Орешкина, Н.Ю. Райгородская, Н.В. Болотова \\ ФГБОУ ВО Саратовский ГМУ им. В.И. Разумовского Минздрава РФ
}

\begin{abstract}
АКТУАЛЬНОСТЬ: нарушение менструального цикла (НМЦ) является распространенной патологией полового развития у девочек с ожирением.

Становление менструальной функции обеспечивается системой нейроэндокринных и метаболических взаимодействий.

Метаболические нарушения, формирующиеся при ожирении, хорошо изучены, однако нет убедительных данных об их влиянии на нейроэндокринную регуляцию менструального цикла у подростков.
\end{abstract}

ЦЕЛЬ ИССЛЕДОВАНИЯ: оценить Взаимосвязи между нейроэндокринными и метаболическими показателями у девочек с ожирением и НМЦ

ПАЦИЕНТЫ И МЕТОДЫ: обследованы 42 девочки 14-16 лет с менструальным возрастом более 2 лет. Основная группа - 23 пациентки с НМЦ на фоне ожирения, группа контроля - 25 здоровых девочек 14-16 лет с физиологическим МЦ. В исследование включались девочки с SDS ИМТ более $+1,5$, менструальным возрастом более 2 -х лет при наличии у них олигоменореи либо вторичной аменореи. Исключались девочки с первичной аменорей, аутоиммунными заболеваниями и другой эндокринной патологией.

Обследование включало оценку физического, полового развития; исследование в сыворотке крови метаболических показателей: инсулина, глюкозы, триглицеридов, холестерина и его фракций; и гормональных показателей ФСГ, ЛГ, эстрадиола, лептина, кисспептина. Статистический анализ проводился с использованием методов непараметрической статистики.

PЕЗУЛЬтАТЫ: Все девочки имели средние показатели роста 0,5 [-0,3; 1,25] SDS.

У 17/23 девочек было установлено ожирение различной степени (SDS ИMТ +2 и более), избыток массы тела (SDS ИМТ 1,5-2) отмечался у 6/23 девочек.

Половое развитие всех пациенток соответствовало 4-5 стадии по Таннер, 4 девочки имели старт пубертата с адренархе. Средний возраст менархе составил $11,8[10,7 ; 12,4]$ и свидетельствовал о раннем наступлении менархе относительно группы контроля 12,8 [11,8; 13,7]. У девочек с ожирением выявлены метаболические осложнения в виде дислипидемии у $64,7 \%$ человек, гиперинсулинемии, инсулинорезистентности у 52,9\%.

По результатам гормональных исследований у девочек с ожирением на фоне олигоменореи и аменореи выявлено повышение концентрации ЛГ в сыворотке крови - 8,5 [4,7; 10,9] мМЕ/мл относительно группы контроля - 4,8 $[3,3 ; 6,6](p=0,021)$ при сниженной концентрации эстрадиола $-55,8[27,4 ; 69]$ пг/мл $(p=0,001)$. Уровень ФСГ не имел достоверных различий с показателями здоровых детей. Выявлена повышенная концентрация лептина - 18,4 [16; 34] нг/мл при низком уровне кисспептина - 90,8 [73,1; 110,4] пг/мл, что связано с формированием лептинорезистентности на фоне ожирения. В группе контроля концентрация лептина и кисспептина составила 10 нг/мл $[8,5 ; 11,2]$ и 129,5 пг/мл [103,7;151,1] соответственно.

Для оценки взаимосвязи между метаболическими и гормональными показателями был проведен корреляционный анализ. У девочек с ожирением и НМЦ выявлены прямые корреляции лептина с уровнем базального инсулина $(r=0,36)$, индексом инсулинорезистентности $(r=0,43)$, концентрацией триглицеридов $(r=0,52)$ и ЛПНП в сыворотке крови $(r=0,74)$.

Таким образом, установлено прямое влияние инсулинорезистентности и дислипидемии на развитие гиперлептинемии и лептинорезистентности.

Кисспептин, В свою очередь, отрицательно коррелировал с уровнем лептина $(r=-0,45)$, инсулина $(r=-0,67)$, индексом инсулинрезистентности $(r=-0,45)$, уровнем триглицеридов $(r=-0,5)$ и ЛПНП $(r=-0,4)$, то есть установлена взаимосвязь метаболических показателей с маркером нейроэндокринной регуляции менструального цикла кисспептином. 


\section{СБОРНИК ТЕЗИСОВ}

XVII Российская научно-практическая конференция детских эндокринологов

«Достижения науки в практику детского эндокринолога»

\section{ВЫвОДы:}

1. У девочек с ожирением выявлено нарушение нейроэндокринной регуляции в виде снижения уровня кисспептина, гиперлептинемии и лептинорезистентности;

2. Метаболические нарушения в виде гиперинсулинемии, инсулинорезистентности у $64,7 \%$, дислипидемии у $52,9 \%$

3. На основании корреляционного анализа установлены взаимосвязи метаболических нарушений и нейроэндокринной дисрегуляцией менструального цикла. 